\title{
AN INVESTIGATION OF THE ROSENOW ANTIBODY ANTIGEN SKIN REACTION IN SCHIZOPHRENIA
}

\author{
BY \\ W. P. GURASSA and H. H. FLEISCHHACKER
}

From Shenley Hospital, Near St. Albans, Herts.

In view of Bering's (1951) confirmatory work on the Rosenow antibody-antigen skin reaction in idiopathic epilepsy, it was decided to carry out similar tests at Shenley Hospital with schizophrenic and epileptic groups of patients, in order to see if further confirmation could be obtained, particularly in schizophrenia.

Rosenow's findings have been reported extensively $(1947,1948 \mathrm{a}, 1948 \mathrm{~b}$ ), but so far the only confirmatory work is that of Bering. In essence, Rosenow believes that a streptococcus of the alpha viridans type plays a significant part in the aetiology of a wide variety of diseases, among which are included epilepsy, schizophrenia, and arthritis. He claims to have demonstrated, using a variety of tests, that patients suffering from any of these groups of diseases harbour alpha-haemolytic streptococci of different types in the naso-pharynx, which are in some ways specific for patients suffering from that particular disorder or group of disorders. One of the ways in which this can be most readily demonstrated is by a cutaneous reaction to an intradermal injection of specific streptococcal antibody, or antigen (Rosenow, 1948c). For practical purposes he finds that a specially prepared antibody, designated " thermal antibody", and prepared according to a carefully described technique, is equivalent to natural antibody prepared by the immunization of animals. According to Rosenow (1948b), this substance, when injected into the skin of patients suffering from diseases similar to those in which the streptococci, from which antibodies have been prepared, were first isolated, produces a higher proportion of large erythematous reactions than when the same substance is injected into well persons, or persons suffering from other disorders. The differences in response so produced appear convincing even without careful statistical analysis. Furthermore, Bering (1951) demonstrated statistically in his own experiments that these findings, in epilepsy at least, are significant beyond all reasonable doubt.

\section{Methods}

Material for use in testing was obtained direct from Dr. Rosenow, and had been prepared by him according to the techniques described and found to give significant results in patients in the U.S.A. These were sent to us in rubber-capped bottles, labelled $A, B, C$, and $F$. Substance $A$ consisted of thermal antibody prepared from cultures of alpha-haemolytic streptococci, isolated from the naso-pharynx of patients suffering from schizophrenia, $B$ from patients with epilepsy, $C$ from patients with arthritis, and $F$ from people who were clinically well at the time. Two sets of these were sent over by air, and one set (selected by tossing a penny) was immediately returned to Dr. Rosenow for testing on American patients to confirm that no change had occurred as a result of transit, and he was in fact able to confirm that this was so.

\section{Case Material}

Patients known personally to only one of us (W. P. G.) were selected according to the diagnosis. Later, after all the tests had been performed, this was confirmed or rectified by both of us, on scrutinizing the case records and interviewing patients where any doubt existed. Atypical features were also noted. All patients were submitted to testing by three observers, under standard conditions of lighting. There was some variation in room temperature, because most patients were tested on cold days, and the others when the weather was warmer. According to Dr. Rosenow (personal communication) the temperature of the wards had no significant influence on cutaneous reactions in his series.

Patients.-These were male patients, mainly long-stay, living for the most part in close association with one another, although suffering from different disorders. Sixty-seven patients were tested in all, and among these were 40 schizophrenics, 16 epileptics, and 11 patients suffering neither from epilepsy nor schizophrenia, to act as controls. Of this last group there were five with general paralysis of the insane (non-convulsive), two manic-depressives, and four with personality disorders.

\section{Technique}

The technique was applied as described by Rosenow (1948b). The volar aspect of the forearm was used for all injections, and cutaneous tests were made by injecting 
intradermally, as superficially as possible, $0.03 \mathrm{ml}$. of each solution. Separate clean and sterile syringes were used in each series of tests. Furthermore, each syringe was clearly labelled $A, B, C$, or $F$, and was used only for the appropriate test substance. Tests were also carried out to show the influence of the quantity injected, but no significant changes were observed whether 0.03 plus or minus 0.01 of a millilitre was injected. It was usually possible not to exceed this error. No attempt was made to discover what drugs the patients were taking at the time, since Rosenow (1955) claims that in epileptics and in schizophrenics drugs such as epanutin, phenobarbitone, or chlorpromazine have little or no effect on the size of cutaneous reactions. Frenquel, which was not used in any case in this series, does apparently significantly increase reactions. No attempt was made to establish in the epileptic patients the relationship in time between testing and occurrence of seizures, although Bering (1951) and Rosenow (1948b) have claimed that the size of the reaction does vary in this respect.

\section{Results and Conclusions}

Schizophrenic Group.-Forty schizophrenic patients were tested, their ages varying from 21 to 55 . No influence was noted in relationship to age or duration of illness nor to the type of illness.

\begin{tabular}{l|c|c|c|c}
\hline & $A$ & $B$ & $C$ & $F$ \\
\cline { 2 - 5 } Average responses (sq. cm.) & 4 & $3 \cdot 6$ & $2 \cdot 5$ & 2 \\
Range of responses (sq. cm.) & $0-15$ & $0-24$ & $0-17$ & $0-10$ \\
\hline
\end{tabular}

All responses were measured by square centimetres of erythema, which was usually maximal about five minutes after injection, and agreed upon by all three observers, using a standard series of circles on a transparent $x$-ray film, supplied by Dr. Rosenow.

Positive reactions, as defined by Rosenow (1948b), are those greater than $5 \mathrm{sq}$. $\mathrm{cm}$. If this value is cases. Ten patients were positive both to $A$ and $B_{3}^{\circ}$ and not to $C$ or $F$. Eleven patients showed greatero reactions to $B$ than to $A$, and two of these were positive to $B$ alone, and one to $B$ and $F$ alone. Onlye three patients out of the 40 showed hardly anyo reaction to any of the antibodies, that is, less than $2 \mathrm{sq} . \mathrm{cm}$. Two of these were the most normafs clinically, in behaviour and appearance. Three casesreacting to $A$ only and showing no response to the other three antibodies were all atypical with cycloid: features. Of the four schizophrenic patients positive $\overrightarrow{\overline{=}}$ to $B$ and not to $A$, one had had a leucotomy, buto the other three presented no unusual features.

Epileptic Group (Aged 22-59).-Sixteen patients $\frac{\overline{\bar{T}}}{\sqrt{5}}$ were tested. These were divided into the following $\mathbb{Q}$ groups, namely, idiopathic, eight; traumatic, three, and aetiology doubtful, five.

\begin{tabular}{|c|c|c|c|c|c|}
\hline & $\boldsymbol{A}$ & $\boldsymbol{B}$ & $\boldsymbol{C}$ & $F$ & $\vec{\nabla}$ \\
\hline Average responses of the & $3 \cdot 5$ & $2 \cdot 6$ & $3 \cdot 3$ & 1.0 & S \\
\hline $\begin{array}{l}\text { Range of responses (sq. cm.) } \\
\text { Positive reactions: idiopathic } \\
\text { epilepsy }\end{array}$ & $\underset{2 / 8}{0-11}$ & $\frac{0-12}{3 / 8}$ & $\begin{array}{c}0-20 \\
0 / 8\end{array}$ & $\begin{array}{c}0-5 \\
0 / 8\end{array}$ & $\bar{\tau}$ \\
\hline
\end{tabular}

Two of the three positive to $B$ were also positige to $A$. One with a greater response to $A$ was epileptic of late onset. The average size of respons of idiopathic cases was: $A, 3.5$ sq. cm.; $B, 2.75$ sg. cm.; $C, 2$ sq. cm.; $F, 0.375$ sq. $\mathrm{cm}$.

Of the three traumatic cases, one was positive $B$, one positive to $A$, but none to $C$, and one did not $\overrightarrow{0}$ react at all to any of the substances injected. Fise out of the 16 epileptics tested did not react to any of the test substances, and these were found in allo three groups, although housed in the same wards, and living in close contact with other patients tested.

$\left.\begin{array}{r}A \\ \hline 16 / 40 \\ 16 / 40\end{array}\right\} 24 / 40$

taken as critical, we found the above in schizophrenic patients.

It was also noted that of the 16 patients reacting positively to $A$, eight also reacted positively to $B$, and one to $C$. Fourteen out of 40 schizophrenic patients showed some degree of reaction to all injections, but in 10 of these the reactions to $A$ and $B$ were greater than $C$ and $F$. When the results of the schizophrenic group were examined according to the positive or negative reactions, no significant difference was found in the two groups, each containing an equal proportion of borderline or doubtful

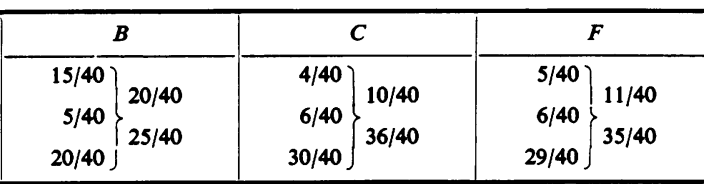

Non-epileptic, Non-schizophrenic Group.-This:miscellaneous group consisted of 11 patients as 3 . described above, ages ranging from 35 to 65 . The average reactions of this group were:-

\begin{tabular}{|c|c|c|c|c|}
\hline & $A$ & $\boldsymbol{B}$ & $C$ & $\boldsymbol{F}$ \\
\hline $\begin{array}{l}\text { Average responses (sq. cm.) } \\
\text { Range of responses (sq. cm.) } \\
\text { Positive cases }\end{array}$ & $\begin{array}{l}4 \\
0-11 \\
4 / 11\end{array}$ & $\begin{array}{l}3 \\
0-12 \\
3 / 11\end{array}$ & $\begin{array}{l}2 \\
0-5 \\
2 / 11\end{array}$ & $\begin{array}{l}1 \cdot 6 \\
0-5 \\
2 / 11\end{array}$ \\
\hline
\end{tabular}

Of the five cases of G.P.I., three were positive to $A \stackrel{N}{N}$ and $B$, and one other reacted more to $A$ and $B$ than 
to $C$ and $F$, although not reaching the critical value of $5 \mathrm{sq} . \mathrm{cm}$. Of those four suffering from personality disorders, one was positive to $A$ and the others were negative. The two manic depressive patients were both positive to $C$ only. One of these had sciatica, and the other was osteo-arthritic.

From these results it can be seen that the tests do not seem clearly to distinguish between any of the three groups of patients tested.

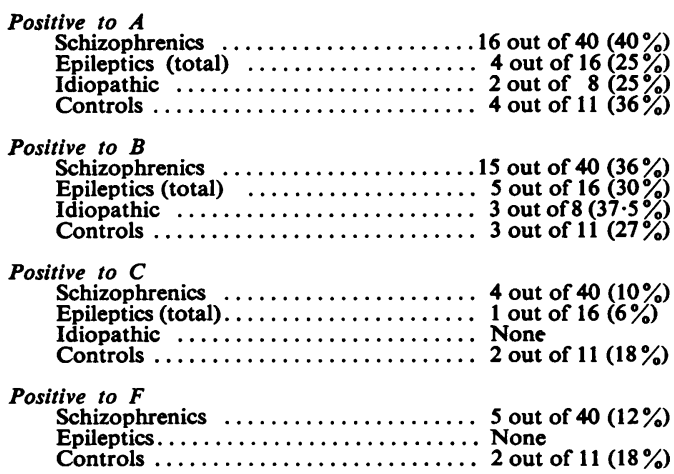

While the total numbers are small, the results have been expressed as percentages to enable easy comparison with Rosenow's (1948b) figures, which are also expressed in the same way. In the case of schizophrenics at least the error produced by so doing remains reasonably small.

Average Responses of Three Groups Compared.Responses to $A$ and $B$ are consistently and considerably greater than to $C$ and $F$ in all groups, and are as follows:-

\begin{tabular}{|c|c|c|c|c|}
\hline & $A$ & $\boldsymbol{B}$ & $C$ & $\boldsymbol{F}$ \\
\hline $\begin{array}{l}\text { Schizophrenics } \\
\text { Epileptics (idiopathic) } \\
\text { Controls }\end{array}$ & $\begin{array}{r}4 \\
3 \cdot 5 \\
4\end{array}$ & $\begin{array}{l}3 \cdot 6 \\
2 \cdot 75 \\
3\end{array}$ & $\begin{array}{r}2 \cdot 5 \\
2 \\
2\end{array}$ & $\begin{array}{l}2 \\
0.375 \\
1.6\end{array}$ \\
\hline
\end{tabular}

If we examine the above results we see that a slightly greater proportion of schizophrenics react to $A$ than to $B$, and a slightly greater proportion of epileptics react to $B$ than to $A$. However, both groups show a significantly greater proportion of reactors to $A$ and $B$ than they do to $C$ and $F$. Considered in terms of the actual size of response rather than the number of persons reacting in any group, again we find that both schizophrenics and epileptics show a greater average size of response to $A$ and $B$ than they do to $C$ and $F$. However, this tendency is also present to an equivalent degree in the control groups. Also, the control group shows a greater number of positive reactors to $A$ and $B$ than to $C$ and $F$. It is our opinion, therefore, that

these results are in no way specific for the groups tested. Looking at Rosenow's (1948b) findings, we see that he claims the following average responses:-

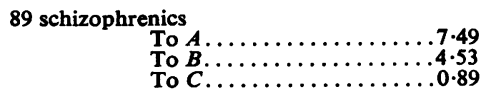

41 idiopathic epileptics selected without regard to severity or contact with schizophrenic patients

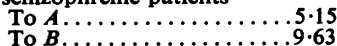

To $C \ldots \ldots \ldots \ldots .2 \cdot 45$

24 cases of G.P.I. without fits

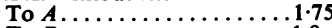

To $B \ldots \ldots \ldots \ldots \ldots \ldots \ldots \ldots$

To $C \ldots \ldots \ldots \ldots \ldots \ldots \ldots .89$

Our figures show no such trend as those of Rosenow, in whose results the average response of schizophrenics is far greater to the antibody derived from schizophrenic patients, the average response of epileptics is far greater to the antibody derived from epileptics, and the average response of cases of G.P.I. is negative to all the antibodies used. It will be noted, however, that many of Rosenow's schizophrenics react quite strongly to $B$ as well as to $A$ and many of his epileptics react to $A$ as well as to $B$.

Expressed as percentages of positive results in these groups, Rosenow's (1948b) figures differ decidedly from ours.

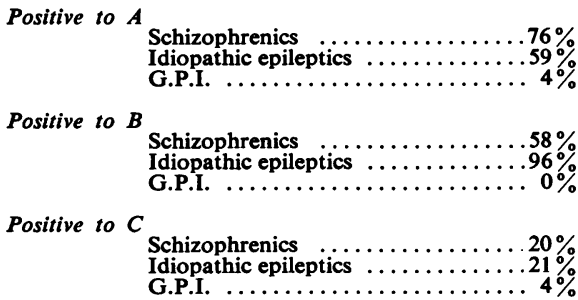

Positive to $A$

Schizophrenics

Idiopathic epileptics $\ldots \ldots \ldots \ldots \ldots \ldots .76 \%$

G.P.I. $\ldots \ldots \ldots \ldots \ldots \ldots \ldots \ldots \ldots \ldots 4 \%$

Positive to $B$

Schizophrenics $\ldots \ldots \ldots \ldots \ldots \ldots . \ldots 8 \%$

Idiopathic epileptics $\ldots \ldots \ldots \ldots \ldots \ldots 96 \%$

Positive to $C$

Schizophrenics $\ldots \ldots \ldots \ldots \ldots \ldots 20 \%$

\begin{tabular}{l} 
Idiopathic epileptics $\ldots \ldots \ldots \ldots \ldots \ldots \ldots 21 \%$ \\
G.P.I. $\ldots \ldots \ldots \ldots \ldots \ldots \ldots \ldots \ldots \ldots \ldots$ \\
\hline
\end{tabular}

Here again, there is a large difference, in that only $40 \%$ of our schizophrenics were positive to $A$, $37.5 \%$ of our epileptics were positive to $B$, and 36 and $27 \%$ of our miscellaneous group, including patients with G.P.I., were positive to $A$ and $B$ respectively. Although the numbers of cases we have tested is small in comparison with Rosenow's series (1948b), in the schizophrenic group at least the discrepancy between the proportion of positive reactors and average responses and those found by Rosenow (1948b) fails to support his findings. In our opinion, these substances are not specific in any way for the groups of chronic patients tested. An explanation is still required, however, as to why it is that patients of all groups react more to $A$ and $B$ antibodies than they do to $C$ and $F$. This is also true of Rosenow's findings. 
These results agree in principle with those obtained by one of us (H. H. F.) in former studies (1953-54) which were carried out entirely blind. Dr. Rosenow had sent over four antibodies labelled $A, B, C$, and $F$, together with a control solution containing no antibodies. Tests were carried out in September, 1953, using eight normal controls at first from the laboratory and nursing staff. Amongst others some very large reactions were obtained, but these were due to the syringes not having been allowed to cool down sufficiently after sterilization. When this error was excluded only small reactions occurred.

Then 19 male schizophrenics and 21 male controls were selected from their case notes, the individual patients being unknown to the experimenter when they came up for injection. Only after the results had been recorded by three observers were the identity and diagnoses of the patients revealed. Then the findings obtained in the individual patients were tabulated according to the symbol of the substances to which they reacted, and these results were sent to Dr. J. N. Cumings of the National Hospital, Queen's Square, London, who had kindly agreed to act as " intermediary". After this, Dr. Rosenow made known the nature of the solutions to Dr. Cumings, who then gave us the relevant information, that is, as to whether $A, B, C$, and $F$ were derived from schizophrenic, epileptic, arthritic, or well person groups. The results were entirely contradictory. Dr. Rosenow was informed of this, and at his request the solutions were returned to him for re-testing. He reported that some of the antibodies had deteriorated. It was then decided to repeat the test the following summer (1954) using a fresh set of thermal antibodies provided by Dr. Rosenow, Dr. Cumings again acting as intermediary. Experimental conditions were altered in two respects: (1) The patients were selected by someone not concerned with the testing. (2) For purposes of measurement, circles on $x$-ray films kindly sent by Dr. Rosenow were used.

The following positive reactions were obtained in 60 male patients:-

\begin{tabular}{l|c|c|c|c}
\hline & $A$ & $B$ & $C$ & $F$ \\
\hline $\begin{array}{l}\text { Schizo- } \\
\text { phrenics }\end{array}$ & $17 / 33(51 \%)$ & $17 / 33(51 \%)$ & $3 / 33(9 \%)$ & $6 / 33(18 \%)$ \\
Epileptics & $4 / 6$ & $4 / 6$ & $1 / 6$ & $4 / 6$ \\
Controls & $2 / 21$ & $3 / 21$ & $0 / 21$ & $2 / 21$ \\
\hline
\end{tabular}

These results differ only in a few minor respects from those described in the main part of this paper, namely, that (1) average reactions were on the whole larger, possibly due to the tests being carried out in the summer. (2) There was a somewhat greater proportion of positive reactors in the typical schizo- phrenic group (13 out of 17). On the other hand, 11 out of these same 17 people reacted positively to the epileptic antibody.

A group of eight old organic controls with dry skins gave negative reactions. Another group of $\underset{0}{\epsilon}$ four young mental defectives gave average responses $T$ to all solutions of the same order as those obtained in typical schizophrenics.

\section{Summary and Conclusions}

In this work an attempt has been made to confirm the specificity of Rosenow's antibody-antigen skin $\overline{0}$ reactions, especially in schizophrenia. In three series $\frac{\bar{\sigma}}{2}$ of tests carried out since 1953 (two of them "blind"), $\frac{\overline{\bar{F}}}{\bar{\alpha}}$ we were unable to confirm that this reaction was $\overparen{D}$ specific or of diagnostic value in the group of patients tested, i.e., Rosenow antibodies failed to distinguish between schizophrenic and epileptic $\vec{\circ}$ groups of patients. In the first series, the results $\overrightarrow{\vec{\omega}}$ were entirely contradictory, and Dr. Rosenow, after $\stackrel{\sigma}{\omega}$ re-testing using the same materials, found that some deterioration of the antibodies had taken place.

In the next two series, 127 patients were tested $\underset{\sim}{\sim}$ (73 schizophrenics, 22 idiopathic and traumatie epileptics, and 32 controls suffering from neitho of these disorders). The following results weet $\vec{\Delta}$ obtained:-

\begin{tabular}{l|c|c|c|c|}
\hline Positive to: & $A$ & $B$ & $C$ & $F$ \\
\hline $\begin{array}{l}\text { Schizo- } \\
\text { phrenics }\end{array}$ & $33 / 73(45 \%)$ & $32 / 73(45 \%)$ & $7 / 73(10 \%)$ & $11 / 73(15 \%$ \\
$\begin{array}{l}\text { Idiopathic } \\
\text { epileptics }\end{array}$ & $6 / 14(43 \%)$ & $7 / 14(50 \%)$ & $1 / 14(7 \%)$ & $4 / 14(28 \%$ 席 \\
Controls & $6 / 32(18 \%)$ & $6 / 32(18 \%)$ & $2 / 32(6 \%)$ & $4 / 32(12 \%)$ \\
\hline
\end{tabular}

From our findings we may conclude that (1) thermal antibodies prepared by Dr. Rosenow from $\overline{0}$ streptococci, isolated and cultured from groups of $\frac{\partial}{D}$ patients with schizophrenia $(A)$ and epilepsy $(B), \stackrel{\mathbb{Q}}{\varrho}$ produce larger reactions when injected into patients $\overrightarrow{\vec{O}}$ suffering from schizophrenia and epilepsy than do 3 antibodies derived from streptococci, isolated and cultured from patients suffering from arthritis $(C)$, ․․ or well persons $(F)$.

Likewise, these same substances $A$ and $B$ produce $\frac{5}{0}$ a greater proportion of positive responses in patients 0 suffering from epilepsy and schizophrenia than do substances $C$ and $F$.

In a control series of patients suffering from neither $₹$ epilepsy nor schizophrenia the average responses 0 are slightly greater to $A$ and $B$ than to $C$ and $F$. The proportion of positive responses is also greater, but less than half of that found in the schizophrenic group.

An interesting impression requiring further in- N vestigation is that people who are clinically well and N patients in any of the groups tested who appear to 
behave relatively normally tend to react negatively to all four substances. However, it was not the purpose of this paper to establish this point.

We should like to thank all those who have helped us with this work, particularly Mr. Warne and Mr. Hadley in the laboratory, members of the nursing staff at Shenley Hospital, and Miss E. Fellowes for her secretarial help. We should also like to thank Dr. E. C. Rosenow for his helpful cooperation and encouragement in carrying out this study, and Dr. S. T. Hayward, of Shenley Hospital, for permission to carry out the work.

\section{REFERENCES}

Bering, E. A., Jr. (1951). J. Neurol. Neurosurg. Psychiat., 14, 205.

Rosenow, E. C. (1947). Postgrad. Med., 2, 346.

(1948a). Ibid., 3, 124

- (1948b). Ibid., 3, 367.

(1948c). Ibid., 3, 367. 61 . 485

(1955). J. nerv. ment. Dis., 122, 321

\section{THE FEBRUARY (1958) ISSUE}

The February (1958) issue contains the following papers:-

The Relative Merits of Encephalography and Ventriculography for the Investigation of Intracranial Tumours. Gösta Norlén and Ingmar Wickbom.

Ischaemic and Post-Ischaemic Numbness and Paraesthesiae. P. W. Nathan.

The Surgical Prognostic Significance of the Electroencephalographic Prediction of Ammon's Horn Sclerosis in Epileptics. W. A. Kennedy and Denis Hill.

A Report of Two Cases of the Juvenile Form of Amaurotoc Familial Idiocy (Cerebromacular Degeneration). Michael Jefferson and M. L. Rutter.

Spinal Angioma with Symptoms in Pregnancy. M. J. D. Newman.

Pulsating Exophthalmos in von Recklinghausen's Disease. Charles Langmaid and Alex Daws.

Optic Atrophy and Nerve Deafness in Diabetes Mellitus. D. A. Shaw and L. J. P. Duncan.

Sodium Amytal and Extraversion. S. G. Laverty.

A Controlled Trial of Methyl Phenidate (Ritalin) in the Treatment of Depressive States. A. A. Robin and S. Wiseberg.

Epinephrine Metabolites and Pigmentation in the Central Nervous System in a case of Phenylpyruvic Oligophrenia. J. H. Fellman.

Proceedings of the Society of British Neurological Surgeons: 56th Meeting.

Book Reviews.

A number of copies are still available and may be obtained from the Publishing Manager, British Medical Association, Tavistock Square, W.C.1, price 17s. $6 d$. 